Article

\title{
Oscillation Conditions for Certain Fourth-Order Non-Linear Neutral Differential Equation
}

\author{
Ioannis Dassios ${ }^{1, *}$ and Omar Bazighifan ${ }^{2,3}$ (D) \\ 1 AMPSAS, University College Dublin, D04 Dublin, Ireland \\ 2 Department of Mathematics, Faculty of Science, Hadhramout University, Hadhramout 50512, Yemen; \\ o.bazighifan@gmail.com \\ 3 Department of Mathematics, Faculty of Education, Seiyun University, Hadhramout 50512, Yemen \\ * Correspondence: ioannis.dassios@ucd.ie
}

Received: 18 May 2020; Accepted: 18 June 2020; Published: 2 July 2020

\begin{abstract}
In this work, new conditions were obtained for the oscillation of solutions of fourth-order non-linear neutral differential equations (NDEs) using the Riccati technique. These oscillation criteria complement and improve those of Chatzarakis et al. (2019). Symmetry plays an important role in determining the right way to study these equation. An example is given to illustrate our theory.
\end{abstract}

Keywords: oscillation; non-linear; neutral; differential; Riccati; fourth order

\section{Introduction}

Neutral differential equations (NDEs) are differential equations with delays, where the delays can appear in both the state variables and their time derivatives. In general, there is considerable interest in studying this type of equation because several phenomena can be modelled using delay differential equations. In [1-3], systems of differential equations with delays were used to study the dynamics and stability properties of electrical power systems. Other examples include macroeconomic models, and studies of their stability properties [4-6]. Finally, properties of delay differential equations were used in the study of singular fractional order differential equations $[7,8]$, and other types of fractional operators such as the fractional nabla applied to difference equations where the memory effect appears $[9,10]$. NDEs have many applications in applied mathematics [11-15], physics, and engineering problems [16,17].

The oscillation of NDEs has been further developed in recent years. For some recent results, see [17-31]. and for results of fourth-order non-linear neutral differential equations, we recommend [32-41] and their references therein. We consider the following class of fourth-order non-linear NDE:

$$
L_{x}^{\prime}+q(y) x^{\alpha}(\pi(y))=0, y \geq y_{0}
$$

where $L_{x}=r(y)\left(w^{\prime \prime \prime}(y)\right)^{\alpha}$ and $w(y):=x(y)+p(y) x(g(y))$. Throughout this paper, we suppose that:

$\left(S_{1}\right) \alpha$ is quotient of odd positive integers,

$\left(S_{2}\right) r, p, q \in C\left[y_{0}, \infty\right), r(y)>0, r^{\prime}(y) \geq 0, q(y)>0,0 \leq p(y)<p_{0}<1, \pi, g \in C\left[y_{0}, \infty\right)$, $\pi, g \leq y, \lim _{y \rightarrow \infty} \pi, g=\infty$, and:

$$
\int_{y_{0}}^{\infty} \frac{1}{r^{1 / \alpha}(s)} \mathrm{d} s<\infty
$$

In addition, if we obtain a solution $x$, then it must satisfy:

$$
x \in C^{3}\left[y_{x}, \infty\right), y_{x} \geq y_{0}, r(y)\left(w^{\prime \prime \prime}(y)\right)^{\alpha} \in C^{1}\left[y_{x}, \infty\right) .
$$


We are interested, however, in $\sup \{|x(y)|: y \geq T\}>0, \forall T \geq y_{x}$. Oscillation can be rigorously studied by applying inverse techniques but can be particularly difficult sometimes given the non-linearity. In [36], the authors obtained results for Equation (1) when $p \in[0,1)$. Chatzarakis et al. [36] published results for the NDE:

$$
\left(r(y)\left(w^{\prime \prime \prime}(y)\right)^{\alpha}\right)^{\prime}+\int_{a}^{b} q(y, s) f(x(g(y, s))) \mathrm{d} s=0,
$$

when:

$$
\int_{y_{0}}^{\infty} \frac{1}{r^{1 / \alpha}(s)} \mathrm{d} s=\infty
$$

In this article, it was proven that the equation is oscillatory if:

$$
\int_{y_{0}}^{\infty}\left(\phi^{*}(y)-\left(\frac{3}{\alpha+1}\right)^{\alpha+1}\left(\frac{2}{\lambda_{0}}\right)^{\alpha} y^{2-3 \alpha} r(y)\right) d s=\infty,
$$

where:

$$
\phi^{*}(y)=k t^{3} Q(y)(1-p)^{\alpha}(\pi(y, a) / y)^{3 \alpha} .
$$

In [24], the authors proved that:

$$
\left(r(y)\left(w^{(n-1)}(y)\right)^{\alpha}\right)^{\prime}+\int_{a}^{b} q(y, s) f(x(g(y, s))) \mathrm{d} s=0
$$

is oscillatory if:

$$
\int_{y_{0}}^{\infty}\left(k \rho(y) Q(y)-\frac{1}{4 \lambda}\left(\frac{\rho^{\prime}(y)}{\rho(y)}\right)^{2} \eta(y)\right) d s=\infty .
$$

Agarwal et al. [42,43] considered the equation:

$$
\left(r(y)\left(x^{(n-1)}(y)\right)^{\alpha}\right)^{\prime}+q(y) x(\pi(y))=0,
$$

and proved the following two interesting Theorems:

Theorem 1 (See [42]). Let $\int_{y}^{\infty} q(s) d s<\infty$ such that:

$$
\liminf _{y \rightarrow \infty} \int_{y}^{\pi(y)} s^{n-2}\left(\int_{s}^{\infty} q(u) d u\right)^{1 / \alpha} d s>\frac{(n-2) !}{e}
$$

and:

$$
\liminf _{y \rightarrow \infty} \int_{y}^{\pi(y)}(\pi(s)-s)^{n-2}\left(\int_{s}^{\infty} q(u) d u\right)^{1 / \alpha} d s>\frac{(n-2) !}{e},
$$

then Equation (4) is oscillatory.

Theorem 2 (See [43]). If:

$$
\limsup _{y \rightarrow \infty} \frac{y^{n-1}}{(n-1) !}\left(\int_{y}^{\infty} q(s) d s+\frac{\theta \alpha}{2(n-2) !} \int_{y}^{\infty} s^{n-2}\left(\int_{s}^{\infty} q(u) d u\right)^{(\alpha+1) / \alpha} d s\right)^{1 / \alpha}>1,
$$

for constants $\theta \in(0,1)$, then Equation (4) is oscillatory.

The remainder of this paper is organized as follows: In Section 2, we provide Lemmas that we use as tools in our main results in Section 3. Using these Lemmas and the Riccati transform, we prove the 
oscillation of Equation (1), and also provide an example. The following notation is adopted throughout the paper:

$$
\begin{aligned}
\chi(y) & =\int_{y}^{v} r^{\frac{-1}{\alpha}}(s) d s, B_{1}(y)=\frac{\theta^{\prime}(y)}{\theta(y)}, \\
B_{2}(y) & =\theta(y) q(y)(1-p(\pi(y)))^{\alpha}
\end{aligned}
$$

and

$$
B_{3}(y)=\alpha \varepsilon \frac{\pi^{2}(y) \phi \pi^{\prime}(y)}{(\theta(y) r(y))^{1 / \alpha}} .
$$

\section{Some Auxiliary Lemmas}

The following Lemma has been proved:

Lemma 1 ([18], Lemma 2.1). Let $F>0$ and $E$ be constants. Then:

$$
E x-F x^{(\alpha+1) / \alpha} \leq \frac{\alpha^{\alpha}}{(\alpha+1)^{\alpha+1}} \frac{E^{\alpha+1}}{F^{\alpha}} .
$$

Lemma 2 ([11], Lemma 2.2.3). Let $x^{(n)}(y)$ is of fixed sign and $x^{(n-1)}(y) x^{(n)}(y) \leq 0$ for all $y \geq y_{1}$. If $\lim _{y \rightarrow \infty} x(y) \neq 0$, then for every $\lambda \in(0,1)$, there exists $y_{\lambda} \geq y_{1}$ such that:

$$
x(y) \geq \frac{\lambda}{(n-1) !} y^{n-1}\left|x^{(n-1)}(y)\right| \text { for } y \geq y_{\lambda} .
$$

Lemma 3 ([24], Lemma 1.2). Let $x(y)$ be positive and $x^{(n-1)}(y) x^{(n)}(y) \leq 0, y \geq y_{x}$ then there exist constants $\phi \in(0,1)$ and $\varepsilon>0$, such that:

$$
x^{\prime}(\phi y) \geq \varepsilon y^{n-2} x^{(n-1)}(y),
$$

for all sufficiently large $y$.

Lemma 4. Assume that $x$ is an eventually positive solution of Equation (1). Then, three possible cases exist for large enough $y \geq y_{1}$

$$
\begin{aligned}
& \left(\mathbf{S}_{1}\right) \quad w(y)>0, w^{\prime}(y)>0, w^{\prime \prime \prime}(y)>0, w^{(4)}(y) \leq 0, \\
& \left(\mathbf{S}_{2}\right) \quad w(y)>0, w^{\prime}(y)>0, w^{\prime \prime}(y)>0, w^{\prime \prime \prime}(y)<0, \\
& \left(\mathbf{S}_{3}\right) \quad w(y)>0, w^{\prime}(y)<0, w^{\prime \prime}(y)>0, w^{\prime \prime \prime}(y)<0 .
\end{aligned}
$$

\section{Oscillation Criteria}

In this section, we establish new oscillation results for Equation (1). Firstly, we prove the following Lemmas.

Lemma 5. Assume that $x$ is an eventually positive solution of Equation (1). Then:

$$
\left(r(y)\left(w^{\prime \prime \prime}(y)\right)^{\alpha}\right)^{\prime} \leq-q(y)(1-p(\pi(y)))^{\alpha} w^{\alpha}(\pi(y)) .
$$

Proof. Let $x$ be an eventually positive solution of Equation (1). Then, there exists a $y_{1} \geq y_{0}$, such that $x(y)>0, x(\pi(y))>0$ and $x(g(y))>0$ for $y \geq y_{1}$. From the definition of $w$, we obtain:

$$
\begin{aligned}
x(y) & \geq w(y)-p(y) x(g(y)) \\
& \geq w(y)-p(y) w(g(y)) \\
& \geq(1-p(y)) w(y),
\end{aligned}
$$


which, with Equation (1), gives:

$$
\left(r(y)\left(w^{\prime \prime \prime}(y)\right)^{\alpha}\right)^{\prime}+q(y)(1-p(\pi(y)))^{\alpha} w^{\alpha}(\pi(y)) \leq 0 .
$$

The proof is complete.

Lemma 6. Assume that $x$ is an eventually positive solution of Equation (1) and that $\left(\mathbf{S}_{1}\right)$ holds. Let there exist a function $\theta \in C^{1}\left(\left[y_{0}, \infty\right), \mathbb{R}^{+}\right)$and constants $\phi \in(0,1), \varepsilon>0$ such that:

$$
\omega(y):=\theta(y) \frac{r(y)\left(w^{\prime \prime \prime}(y)\right)^{\alpha}}{w^{\alpha}(\phi \pi(y))},
$$

then:

$$
\boldsymbol{\omega}^{\prime}(y)-B_{1}(y) \omega(y)+B_{2}(y)+B_{3}(y) \omega^{(\alpha+1) / \alpha}(y) \leq 0 .
$$

Proof. Assume that $x$ is an eventually positive solution of Equation (1) and that $\left(\mathbf{S}_{1}\right)$ holds. Using Lemma 5, we obtain that Euation (5) holds. From Equation (6), we see that $\omega(y)>0$ for $y \geq y_{1}$, and using Equation (5), we obtain:

$$
\begin{aligned}
\boldsymbol{\omega}^{\prime}(y) \leq & \theta^{\prime}(y) \frac{r(y)\left(w^{\prime \prime \prime}(y)\right)^{\alpha}}{w^{\alpha}(\phi \pi(y))}+\theta(y) \frac{-q(y) q(y)(1-p(\pi(y)))^{\alpha} w^{\alpha}(\pi(y))}{w^{\alpha}(\phi \pi(y))} \\
& -\alpha \theta(y) \frac{r(y)\left(w^{\prime \prime \prime}(y)\right)^{\alpha} w^{\prime}(\phi \pi(y)) \phi \pi^{\prime}(y)}{w^{\alpha+1}(\phi \pi(y))} .
\end{aligned}
$$

From Lemma 3, we have:

$$
w^{\prime}(\phi \pi(y)) \geq \varepsilon \pi^{2}(y) w^{\prime \prime \prime}(\pi(y))
$$

Thus, we obtain:

$$
\begin{aligned}
\omega^{\prime}(y) \leq & \theta^{\prime}(y) \frac{r(y)\left(w^{\prime \prime \prime}(y)\right)^{\alpha}}{w^{\alpha}(\phi \pi(y))}-\theta(y) q(y)(1-p(\pi(y)))^{\alpha} \\
& -\alpha \theta(y) \frac{r(y)\left(w^{\prime \prime \prime}(y)\right)^{\alpha} \varepsilon \pi^{2}(y) w^{\prime \prime \prime}(\pi(y)) \phi \pi^{\prime}(y)}{w^{\alpha+1}(\phi \pi(y))},
\end{aligned}
$$

which is:

$$
\begin{aligned}
\boldsymbol{\omega}^{\prime}(y) \leq & \theta^{\prime}(y) \frac{r(y)\left(w^{\prime \prime \prime}(y)\right)^{\alpha}}{w^{\alpha}(\phi \pi(y))}-\theta(y) q(y)(1-p(\pi(y)))^{\alpha} \\
& -\alpha \varepsilon \theta(y) \frac{r(y) \pi^{2}(y) \phi \pi^{\prime}(y)\left(w^{\prime \prime \prime}(y)\right)^{\alpha+1}}{w^{\alpha+1}(\phi \pi(y))}
\end{aligned}
$$

where, by using Equation (6), we have:

$$
\begin{aligned}
\mathscr{\omega}^{\prime}(y) \leq & \frac{\theta^{\prime}(y)}{\theta(y)} \mathfrak{\omega}(y)-\theta(y) q(y)(1-p(\pi(y)))^{\alpha} \\
& -\alpha \varepsilon \frac{\pi^{2}(y) \phi \pi^{\prime}(y)}{(\theta(y) r(y))^{1 / \alpha}} \omega^{(\alpha+1) / \alpha}(y),
\end{aligned}
$$

that is,

$$
\omega^{\prime}(y)-B_{1}(y) \omega(y)+B_{2}(y)+B_{3}(y) \omega^{(\alpha+1) / \alpha}(y) \leq 0 .
$$

The proof is complete. 
Lemma 7. Assume that $x$ is an eventually positive solution of Equation (1) and $\left(\mathbf{S}_{2}\right)$ holds. If:

$$
\zeta(y):=\frac{r(y)\left(w^{\prime \prime \prime}(y)\right)^{\alpha}}{\left(w^{\prime \prime}(y)\right)^{\alpha}}
$$

then:

$$
\zeta^{\prime}(y) \leq-q(y)(1-p(\pi(y)))^{\alpha}\left(\frac{\lambda}{2} \pi^{2}(y)\right)^{\alpha}-\alpha \frac{\zeta^{\frac{\alpha}{\alpha}}(y)}{r^{\frac{1}{\alpha}}(y)} .
$$

Proof. Assume that $x$ is an eventually positive solution of Equation (1) and $\left(\mathbf{S}_{2}\right)$ holds. Using Lemma 5 , we obtain that Equation (5) holds. Recalling that $r(y)\left(w^{\prime \prime \prime}(y)\right)^{\alpha}$ is non-increasing, we obtain:

$$
r^{\frac{1}{\alpha}}(s) w^{\prime \prime \prime}(s) \leq r^{\frac{1}{\alpha}}(y) w^{\prime \prime \prime}(y), s \geq y \geq y_{1} .
$$

So, we find:

$$
w^{\prime \prime \prime}(s) \leq r^{\frac{1}{\alpha}}(y) w^{\prime \prime \prime}(y) r^{\frac{-1}{\alpha}}(s) .
$$

Integrating again from $y$ to $v$, we obtain:

$$
w^{\prime \prime}(y)-w^{\prime \prime}(v) \geq-r^{\frac{1}{\alpha}}(y) w^{\prime \prime \prime}(y) \int_{y}^{v} r^{\frac{-1}{\alpha}}(s) d s .
$$

Letting $v \rightarrow \infty$, we obtain:

$$
x^{\prime \prime}(y) \geq-r^{\frac{1}{\alpha}}(y) x^{\prime \prime \prime}(y) \chi(y),
$$

which yields:

$$
-\frac{r^{\frac{1}{\alpha}}(y) w^{\prime \prime \prime}(y)}{w^{\prime \prime}(y)} \chi(y) \leq 1
$$

Thus, by using Equation (9),we see that:

$$
-\zeta(y) \chi^{\alpha}(y) \leq 1
$$

From Lemma 2, we obtain:

$$
w(y) \geq \frac{\lambda}{2} y^{2} w^{\prime \prime}(y),
$$

for every $\lambda \in(0,1)$ and all sufficiently large $y$. From Equation (9), we see that $\zeta(y)<0$ for $y \geq y_{1}$; using Equations (5) and (13), we obtain:

$$
\begin{aligned}
\zeta^{\prime}(y) & =-q(y)(1-p(\pi(y)))^{\alpha} \frac{x^{\alpha}(\pi(y))}{\left(w^{\prime \prime}(\pi(y))\right)^{\alpha}} \frac{\left(w^{\prime \prime}(\pi(y))\right)^{\alpha}}{\left(w^{\prime \prime}(y)\right)^{\alpha}}-\alpha \frac{\zeta^{\frac{\alpha}{\alpha}}(y)}{r^{\frac{1}{\alpha}}(y)} \\
& \leq-q(y)(1-p(\pi(y)))^{\alpha}\left(\frac{\lambda}{2} \pi^{2}(y)\right)^{\alpha}-\alpha \frac{\zeta^{\frac{\alpha}{\alpha}}(y)}{r^{\frac{1}{\alpha}}(y)} .
\end{aligned}
$$

The proof is complete.

Next, we prove the following Theorem:

Theorem 3. We consider the non-linear NDE in Equation (1). Let a function $\theta \in C^{1}\left(\left[y_{0}, \infty\right)\right.$ exist, $\left.\mathbb{R}^{+}\right)$and constants $\varepsilon \in(0,1), \phi>0$ such that:

$$
\limsup _{y \rightarrow \infty} \int_{y_{0}}^{y}\left(B_{2}(y)-\frac{r(s)}{(\alpha+1)^{\alpha+1}} \frac{\left(\theta^{\prime}(s)\right)^{\alpha+1}}{\left(\varepsilon \theta(s) \pi^{2}(y) \phi \pi^{\prime}(s)\right)^{\alpha}}\right) \mathrm{d} s=\infty
$$


and:

$$
\limsup _{y \rightarrow \infty} \int_{y_{1}}^{y}\left(q(s)(1-p(\pi(s)))^{\alpha}\left(\frac{\lambda}{2} \pi^{2}(s)\right)^{\alpha} \chi^{\alpha}(s)-\frac{\alpha^{\alpha+1}}{(\alpha+1)^{\alpha+1} r^{\frac{1}{\alpha}}(s) \chi(s)}\right) \mathrm{d} s=\infty,
$$

for some constant $\lambda \in(0,1)$. If:

$$
\limsup _{y \rightarrow \infty} \int_{y_{1}}^{y}\left(k q(s)\left(\frac{\pi^{2}(s)}{2}\right)^{\alpha} \chi^{\alpha}(s)-\frac{\alpha^{\alpha+1}}{(\alpha+1)^{\alpha+1} r^{\frac{1}{\alpha}}(s) \chi(s)}\right) \mathrm{d} s=\infty,
$$

for all constant $k>0$, then Equation (1) is almost oscillatory.

Proof. Let $x$ be a non-oscillatory solution of Equation (1) on $\left[y_{0}, \infty\right)$. Assume that $x>0$. From Lemma 4 , we see that three possible cases, $\left(\mathbf{S}_{1}\right),\left(\mathbf{S}_{2}\right)$, and $\left(\mathbf{S}_{3}\right)$. Let $\left(\mathbf{S}_{1}\right)$ hold. Using Lemma 6 , we determine that Equation (7) holds. Thus, from Lemma 1, we set:

$$
E=\theta^{\prime} / \theta, \quad F=\alpha \varepsilon \pi^{2}(y) \phi \pi^{\prime}(y) /(\theta(y) r(y))^{1 / \alpha} \text { and } x=\omega(y) .
$$

Thus, we have:

$$
\omega^{\prime}(y) \leq-B_{2}(y)+\frac{r(y)}{(\alpha+1)^{\alpha+1}} \frac{\left(\theta^{\prime}(y)\right)^{\alpha+1}}{\left(\varepsilon \theta(y) \pi^{2}(y) \phi \pi^{\prime}(y)\right)^{\alpha}} .
$$

Integrating again from $y_{1}$ to $y$, we obtain:

$$
\limsup _{y \rightarrow \infty} \int_{y_{1}}^{y}\left(B_{2}(y)-\frac{r(s)}{(\alpha+1)^{\alpha+1}} \frac{\left(\theta^{\prime}(s)\right)^{\alpha+1}}{\left(\varepsilon \theta(s) \pi^{2}(y) \phi \pi^{\prime}(s)\right)^{\alpha}}\right) \mathrm{d} s \leq \omega\left(y_{1}\right),
$$

which contradicts Equation (14). Assume that $\left(\mathbf{S}_{2}\right)$ holds. From Lemma 7, we determine that Equation (10) holds. Multiplying Equation (10) by $\chi^{\alpha}(y)$ and integrating the resulting inequality from $y_{1}$ to $y$, we obtain:

$$
\begin{aligned}
& \chi^{\alpha}(y) \zeta(y)-\chi^{\alpha}\left(y_{1}\right) \zeta\left(y_{1}\right)+\alpha \int_{y_{1}}^{y} r^{\frac{-1}{\alpha}}(s) \chi^{\alpha-1}(s) \zeta(s) d s \\
\leq & -\int_{y_{1}}^{y} q(s)(1-p(\pi(s)))^{\alpha}\left(\frac{\lambda}{2} \pi^{2}(s)\right)^{\alpha} \chi^{\alpha}(s) d s-\alpha \int_{y_{1}}^{y} \frac{\zeta^{\frac{\alpha}{\alpha}}(s)}{r^{\frac{1}{\alpha}}(s)} \chi^{\alpha}(s) d s .
\end{aligned}
$$

We set:

$$
E=r^{\frac{-1}{\alpha}}(s) \chi^{\alpha-1}(s), F=\frac{\chi^{\alpha}(s)}{r^{\frac{1}{\alpha}}(s)}, x:=-\zeta(s) .
$$

From Lemma 1, we obtain:

$$
\int_{y_{1}}^{y}\left(q(s)(1-p(\pi(s)))^{\alpha}\left(\frac{\lambda}{2} \pi^{2}(s)\right)^{\alpha} \chi^{\alpha}(s)-\frac{\alpha^{\alpha+1}}{(\alpha+1)^{\alpha+1} r^{\frac{1}{\alpha}}(s) \chi(s)}\right) d s \leq \chi^{\alpha}\left(y_{1}\right) \zeta\left(y_{1}\right)+1,
$$

due to Equation (12), which contradicts Equation (15). Assume that $\left(\mathbf{S}_{3}\right)$ holds. Similar to the proof of that of ([44], Lemma 2), a constant $k>0$ exists such that:

$$
k w(y) \leq x(y) .
$$

The conclusion of the proof is similar to that of Similar to the case of $\left(\mathbf{S}_{2}\right)$, we arrive at a contradiction to Equation (16).The proof is complete. 
We now present the following example.

Example 1. For $y \geq 1$, consider the following differential equation:

$$
\left(y^{2}\left(x(y)+\frac{1}{2} x\left(\frac{y}{2}\right)\right)^{\prime \prime \prime}\right)^{\prime}+\frac{q_{0}}{y} x\left(\frac{y}{2}\right)=0,
$$

where $q_{0}>0$ is a constant. Let $\alpha=1, r(y)=y^{2}, \pi(y)=g(y)=y / 2, q(y)=q_{0} / y$, and $p(y)=1 / 2$. Thus, we obtain:

$$
\int_{y_{0}}^{\infty} \frac{1}{r(s)} d s=\int_{y_{0}}^{\infty} \frac{1}{s^{2}} \mathrm{~d} s<\infty
$$

Thus, by Theorem 3, we determine that Equations (14)-(16) are satisfied if $q_{0}>1$. Hence, all solutions of (18) are oscillatory or converge to zero as $y \rightarrow \infty$.

Example 2. For $y \geq 1$, consider the equation:

$$
\left(y^{3}\left(x(y)+p_{0} x\left(\frac{y}{3}\right)\right)^{\prime \prime \prime}\right)^{\prime}+y x(\delta y)=0
$$

where $\delta \in(0,1)$ and $0 \leq p_{0}<1$. Let $\alpha=1, r(y)=y^{2}, \pi(y)=y / 3, g(y)=\delta y, q(y)=y$ and $p(y)=p_{0}$. Thus, we obtain:

$$
\int_{y_{0}}^{\infty} \frac{1}{r(s)} d s=\int_{y_{0}}^{\infty} \frac{1}{s^{3}} \mathrm{~d} s<\infty
$$

Thus, by Theorem 3, we determine that Equations (14)-(16) are satisfied. Hence, all solutions of Equation (18) are oscillatory or converge to zero as $y \rightarrow \infty$.

\section{Conclusions}

In this work, we dealt with the oscillation of a fourth-order non-linear NDEs of the form in Equation (1). We obtained new oscillation criteria for these equations using the Riccati technique. As an extension of this article, we aim to provide oscillation criteria of the Hille, Nehari, and Philos type for Equation (1).

Author Contributions: I.D.: Writing review and editing, formal analysis, investigation, funding and supervision. O.B.: Writing original draft, formal analysis, writing review and editing. All authors have read and agreed to the published version of the manuscript.

Funding: This work is supported by the Science Foundation Ireland (SFI), by funding Ioannis Dassios under Investigator Programme Grant No. SFI/15 /IA/3074.

Conflicts of Interest: The authors declare no conflict of interest.

\section{References}

1. Liu, M.; Dassios, I.; Tzounas, G.; Milano, F. Model-Independent Derivative Control Delay Compensation Methods for Power Systems. Energies 2020, 13, 342. [CrossRef]

2. Liu, M.; Dassios, I.; Tzounas, G.; Milano, F. Stability Analysis of Power Systems with Inclusion of Realistic-Modeling of WAMS Delays. IEEE Trans. Power Syst. 2019, 34, 627-636. [CrossRef]

3. Milano, F.; Dassios, I. Small-Signal Stability Analysis for Non-Index 1 Hessenberg Form Systems of Delay Differential-Algebraic Equations. IEEE Trans. Circuits Syst. Regul. Pap. 2016, 63, 1521-1530. [CrossRef]

4. Dassios, I.; Zimbidis, A.; Kontzalis, C. The Delay Effect in a Stochastic Multiplier-Accelerator Model. J. Econ. Struct. 2014, 3, 1-24. [CrossRef]

5. Dassios, I.; Baleanu, D. Duality of singular linear systems of fractional nabla difference equations. Appl. Math. Model. 2015, 14, 4180-4195. [CrossRef] 
6. Dassios, I. Optimal solutions for non-consistent singular linear systems of fractional nabla difference equations. Circuits Syst. Signal Process. 2015, 34, 1769-1797. [CrossRef]

7. Dassios, I.; Baleanu, D. Optimal solutions for singular linear systems of Caputo fractional differential equations. Math. Methods Appl. Sci. 2020. [CrossRef]

8. Dassios, I.; Baleanu, D. Caputo and related fractional derivatives in singular systems. Appl. Math. Comput. 2018, 337, 591-606. [CrossRef]

9. Dassios, I. A practical formula of solutions for a family of linear non-autonomous fractional nabla difference equations. J. Comput. Appl. Math. 2018, 339, 317-328. [CrossRef]

10. Dassios, I. Stability and robustness of singular systems of fractional nabla difference equations. Circuits Syst. Signal Process. 2017, 36, 49-64. [CrossRef]

11. Agarwal, R.; Grace, S.; O'Regan, D. Oscillation Theory for Difference and Functional Differential Equations; Kluwer Academic Publisher: Dordrecht, The Netherlands, 2000.

12. Agarwal, R.P.; Berezansky, L.; Braverman, E.; Domoshnitsky, A. Nonoscillation Theory of Functional Differential Equations with Applications; Springer: New York, NY, USA, 2012.

13. Agarwal, R.P.; Bohner, M.; Li, W. Nonoscillation and Oscillation: Theory for Functional Differential Equations; Marcel Dekker: New York, NY, USA, 2004; Volume 267.

14. Kiguradze, I.T.; Chanturiya, T.A. Asymptotic Properties Of Solutions of Non-Autonomous Ordinary Differential Equations; Kluwer Academic Publisher: Dordrecht, The Netherlands, 1993.

15. Hale, J.K. Theory of Functional Differential Equations; Springer: New York, NY, USA, 1977.

16. Liu, M.; Dassios, I.; Milano, F. On the Stability Analysis of Systems of Neutral Delay Differential Equations. Circuits Syst. Signal Process. 2019, 38, 1639-1653. [CrossRef]

17. Shi, Y. Oscillation criteria for nth order nonlinear neutral differential equations. Appl. Math. Comput. 2014, 235, 423-429. [CrossRef]

18. Agarwal, R.P.; Zhang, C.; Li, T. Some remarks on oscillation of second order neutral differential equations. Appl. Math. Compt. 2016, 274, 178-181. [CrossRef]

19. Agarwal, R.P.; Bohner, M.; Li, T.; Zhang, C. A new approach in the study of oscillatory behavior of even-order neutral delay differential equations. Appl. Math. Comput. 2013, 225, 787-794. [CrossRef]

20. Baculikova, B.; Dzurina, J.; Li, T. Oscillation results for even-order quasi linear neutral functional differential equations. Electron. J. Differ. Equ. 2011, 2011, 1-9.

21. Li, T.; Han, Z.; Zhao, P.; Sun, S. Oscillation of even-order neutral delay differential equations. Adv. Differ. Equ. 2010, 2010, 1-9. [CrossRef]

22. Moaaz, O. New criteria for oscillation of nonlinear neutral differential equations. Adv. Differ. Equ. 2019, 2019, 484. [CrossRef]

23. Moaaz, O.; Jan Awrejcewicz, O.; Bazighifan, A. New Approach in the Study of Oscillation Criteria of Even-Order Neutral Differential Equations. Mathematics 2020, 12, 197. [CrossRef]

24. Moaaz, O.; Elabbasy, E.M.; Muhib, A. Oscillation criteria for even-order neutral differential equations with distributed deviating arguments. Adv. Differ. Equ. 2019, 297, 1-10. [CrossRef]

25. Moaaz, O.; Dassios, I.; Bazighifan, O. Oscillation Criteria of Higher-order Neutral Differential Equations with Several Deviating Arguments. Mathematics 2020, 8, 402. [CrossRef]

26. Bazighifan, O.; Dassios, I. On the Asymptotic Behavior of Advanced Differential Equations with a Non-Canonical Operator. Appl. Sci. 2020, 10, 3130. [CrossRef]

27. Parhi, N.; Tripathy, A. On oscillatory fourth order linear neutral differential equations-I. Math. Slovaca 2004, 54, 389-410.

28. Xing, G.; Li, T.; Zhang, C. Oscillation of higher-order quasi linear neutral differential equations. Adv. Differ. Equ. 2011, 2011, 1-10. [CrossRef]

29. Zafer, A. Oscillation criteria for even order neutral differential equations. Appl. Math. Lett. 1998, 11, $21-25$. [CrossRef]

30. Zhang, Q.; Yan, J. Oscillation behavior of even order neutral differential equations with variable coefficients. Appl. Math. Lett. 2006, 19, 1202-1206. [CrossRef]

31. Zhang, Q.; Yan, J.; Gao, L. Oscillation behavior of even-order nonlinear neutral differential equations with variable coefficients. Comput. Math. Appl. 2010, 59, 426-430. [CrossRef]

32. Bazighifan, O.; Cesarano, C. Some New Oscillation Criteria for Second-Order Neutral Differential Equations with Delayed Arguments. Mathematics 2019, 7, 619. [CrossRef] 
33. Moaaz, O.; Dassios, I.; Bazighifan, O.; Muhib, A. Oscillation Theorems for Nonlinear Differential Equations of Fourth-Order. Mathematics 2020, 8, 520. [CrossRef]

34. Bazighifan, O.; Dassios, I. Riccati Technique and Asymptotic Behavior of Fourth-Order Advanced Differential Equations. Mathematics 2020, 8, 590. [CrossRef]

35. Bazighifan, O.; Ramos, H. On the asymptotic and oscillatory behavior of the solutions of a class of higher-order differential equations with middle term. Appl. Math. Lett. 2020, 107, 106431. [CrossRef]

36. Chatzarakis, G.E.; Elabbasy, E.M.; Bazighifan, O. An oscillation criterion in 4th-order neutral differential equations with a continuously distributed delay. Adv. Differ. Equ. 2019, 336, 1-9.

37. Bazighifan, O.; Cesarano, C. A Philos-Type Oscillation Criteria for Fourth-Order Neutral Differential Equations. Symmetry 2020, 12, 379. [CrossRef]

38. Bazighifan, O. An Approach for Studying Asymptotic Properties of Solutions of Neutral Differential Equations. Symmetry 2020, 12, 555. [CrossRef]

39. Bazighifan, O. Kamenev and Philos-types oscillation criteria for fourth-order neutral differential equations. Adv. Differ. Equ. 2020, 201, 1-12. [CrossRef]

40. Bazighifan, O.; Ruggieri, M.; Scapellato, A. An Improved Criterion for the Oscillation of Fourth-Order Differential Equations. Mathematics 2020, 8, 610. [CrossRef]

41. Bazighifan, O.; Postolache, M. An improved conditions for oscillation of functional nonlinear differential equations. Mathematics 2020, 12, 552. [CrossRef]

42. Agarwal, R.; Grace, S.R. Oscillation theorems for certain functional differential equations of higher order. Math. Comput. Model. 2004, 39, 1185-1194. [CrossRef]

43. Agarwal, R.; Grace, S.R.; O'Regan, D. Oscillation criteria for certain $\mathrm{n}$ th order differential equations with deviating arguments. J. Math. Anal. Appl. 2001, 262, 601-622. [CrossRef]

44. Baculikova, B.; Dzurina, J. Oscillation of third-order neutral differential equations. Math. Comput. Model. 2010, 52, 215-226. [CrossRef]

(C) 2020 by the authors. Licensee MDPI, Basel, Switzerland. This article is an open access article distributed under the terms and conditions of the Creative Commons Attribution (CC BY) license (http:/ / creativecommons.org/licenses/by/4.0/). 